\title{
Smart interior design of buildings and its relationship to land use
}

\author{
José Amarilio Barbosa (D), Catarina Araújo (D), Ricardo Mateus (i) and Luís Bragança (D)
}

Department of Civil Engineering, University of Minho, Guimarães, Portugal

\begin{abstract}
Architectural design is often associated with aesthetics and style, but it is also very important to building performance and sustainability. There are some studies associating architectural design to the choice for materials from sustainable sources, to indoor air quality, to energy efficiency and productivity. This article takes a step further to analyse how the use of efficient interior design techniques can impact the habitable space in order to improve building sustainability in land use. Smart interior design, a current trend related to the use of efficient and flexible furniture and movable walls in tiny or compact apartments, is analysed. A building with a standard design is used as a case study reference building and compared to a proposed theoretical design alternative using smart interior design techniques. In order to correctly assess sustainability performance, a quantifiable and verified method is used. Results showed that the use of smart interior design techniques can greatly reduce buildings' impact on the environment.
\end{abstract}

\section{ARTICLE HISTORY}

Received 10 September 2015

Revised 11 November 2015

Accepted 11 November 2015

\section{KEYWORDS}

Sustainable buildings; building design; smart interior design; sustainability assessment; land use

\section{Introduction}

Nowadays society is facing several environmental and societal problems. One solution has been to improve the sustainability of the built environment with the green building movement. However, architectural and interior designs are often undervalued as activities with influence in promoting building sustainability. Nevertheless, several authors associate interior design to several key sustainability issues, such as energy consumption, indoor air quality (Lee, 2012; Sorrento, 2012), the selection of sustainable materials (McCoy, 2012) and daylight (Day, Theodorson, \& Van Den Wymelenberg, 2012). Sorrento (2012) also points out that the user requirements, health, safety, welfare and productivity are the concern of the interior designer (Sorrento, 2012), strengthening the connection between interior design and sustainability goals. McCoy goes further asserting that almost all topics or subjects relating to interior design have a direct relationship with sustainability (McCoy, 2012).

Interior design directly affects constructed areas and it is somehow common sense that buildings adopting diverse strategies for the interior design make them more or less spacious. The size, the amount and the arrangement of the compartments inside buildings, together with the predicted occupancy of the building, influences the building performance regarding land use (Barbosa, Araújo, Mateus, \& Bragança, 2015). Nevertheless, no studies were found connecting the interior design to land use, which is surprising considering the impact of the design on the living spaces from the point of view of the size and density of buildings.

It is important to design buildings taking into consideration the impact on land use since this is a key aspect to consider in the design of sustainable buildings. This is due to the rapid increase in population living in urban environments aggravated by poor urban planning. In consequence, urban 
sprawl (proliferation of low-density urban areas in the limits of cities) is occurring in most cities of the world (Amado \& Ribeiro, 2011; Arribas-Bel, Nijkamp, \& Scholten, 2010; Barbosa, Bragança, \& Mateus, 2014a, 2014b; Habibi \& Asadi, 2011; Halleux, Marcinczak, \& van der Krabben, 2012).

In order to be able to design high-performance buildings regarding land use, it is first necessary to be able to quantify buildings' performance. This way, it is possible to compare different solutions in order to select the best ones (Barbosa et al., 2014a). Considering a previous study (Barbosa et al., 2014a), a new assessment method was developed indicating that buildings have better performance the higher the values of functional area (FA) and the number of occupants and the lower the values of the gross floor area (GFA), the building footprint and the allotment area (AA) (Barbosa et al., 2014a). The trend is to build buildings with high spatial efficiency (SE) and high density (in construction and in population).

The argument is that it is possible to improve building sustainability by implementing the concept of smart interior design. Smart interior design can be defined as the use of techniques to increase flexibility of building compartments in order to reduce the amount of constructed areas while maintaining the necessary requirements. These techniques improve the flexibility and adaptability of buildings by increasing the number of possible uses of building compartments over time. These additional functions eliminate the need for additional compartments and allow reducing the area of buildings, while maintaining or even increasing functionality and possibly comfort. At the same time, smart interior design has other co-benefits since it allows reducing the need for construction materials, the production of wastes and the energy consumption for building climatisation, promoting sustainability.

This work studies smart interior design solutions, such as efficient and adaptable furniture, movable walls, and other space-saving techniques and their relation to land-use efficiency (LUE) of buildings. These solutions are tested by the comparison of an existing building to a proposed theoretical design alternative. The comparison is done using quantifiable calculation methods.

\section{Smart interior design techniques and implications}

\section{Examples of smart interior design in buildings}

It is in the early design stages that building solutions should be predicted to increase buildings sustainability levels (Bragança, Vieira, \& Andrade, 2014). Generally, furniture size and weight makes the adaptation of compartments very difficult because the pieces are hard to move or replace. Usually, the selection of furniture is ignored in the design of conventional buildings. As an example, bedrooms are hardly able to be transformed into other functions because conventional beds, wardrobes and commodes are difficult to move. One possible solution for this is the use of smart interior design techniques such as highly efficient and adaptable furniture. This sort of space-saving furniture enables occupants, for example, to rotate and hide horizontal surfaces such as beds and tables to vertical positions against walls with little effort, allowing the easy transformation of building compartments. Adaptable furniture is often associated with efficient storage techniques, such as hidden shelves and drawers inside walls, floors, stairs or furniture pieces, allowing a reduction in the area of compartments and better organisation of space. Other examples of these techniques are chairs and tables that are foldable into smaller pieces which are easier to store and to deploy. These techniques make building compartments dedicated to storage unnecessary.

Although this kind of furniture is not yet widely common, there are some cases using space-saving furniture, such as the case of the Lego Style Apartment (Faircompanies, 2011), in which designers planned the use of adaptable furniture and very efficient storage in a $26 \mathrm{~m}^{2}$ apartment with all the functions of a standard apartment (Figure 1(a)). Another example is the case of the Popup Interactive Apartment, developed at the Technical University of Delft (Figure 1(b)), in which the furniture is made of thin plane elements that are hidden behind walls and slide using mechanical devices under the floor, getting the desired and final shape in specific positions of the apartment (Designboom, 

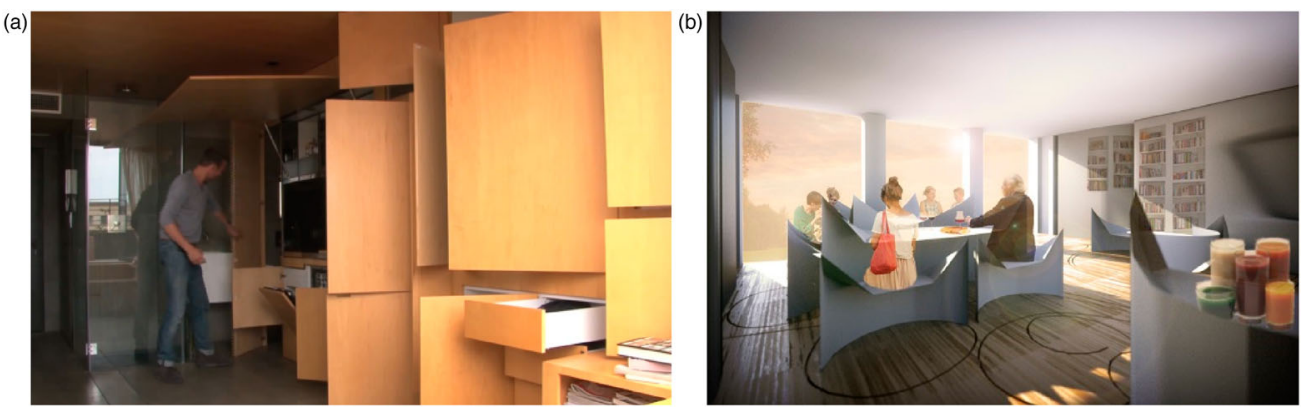

Figure 1. Examples of the use of efficient furniture: (a) Lego Style Apartment (Faircompanies, 2011); (b) Popup Interactive Apartment (Designboom, 2013b).

2013b). These examples show that it is possible to use several space-saving techniques to reduce constructed areas and also address difficulties in adapting compartments due to the inertia of the furniture.

Another issue regarding the adaptation of building compartments is the limitation caused by the existence of static walls, which confine the compartments to a fixed state and area. It is complicated to adapt a compartment to a certain function that normally needs a minimum floor area to one with less than that amount. One solution is the use of movable or operable partition walls (Figure 2). These solutions make it possible to change the configuration of apartments according to user requirements. One possible use of movable partition walls is the transformation of two bedrooms, which could be combined by removing the dividing wall to make a bigger room, living room or even an office. In a conventional apartment the two bedrooms would have the same function permanently, being unoccupied during most of the day. But in an apartment using these systems the two bedrooms could be transformed according to the occupants needs. Considering this, apartment occupants may possibly not need a permanent compartment for the living room and therefore less floor area would be required. Movable walls, besides allowing them to be folded or unfolded relatively quickly, can still deliver high acoustic and thermal proprieties and can even hold doors and windows.

The Changing Places Group of the Massachusetts Institute of Technology (MIT) Media Lab has been performing research about techniques to apply the concepts of adaptable compartments to modern buildings. The CityHome Project develops and tests solutions to reduce the area of compartments using several space-saving techniques combining adaptable and efficient furniture to transformable and movable walls and home automation, creating truly easy to use transformable

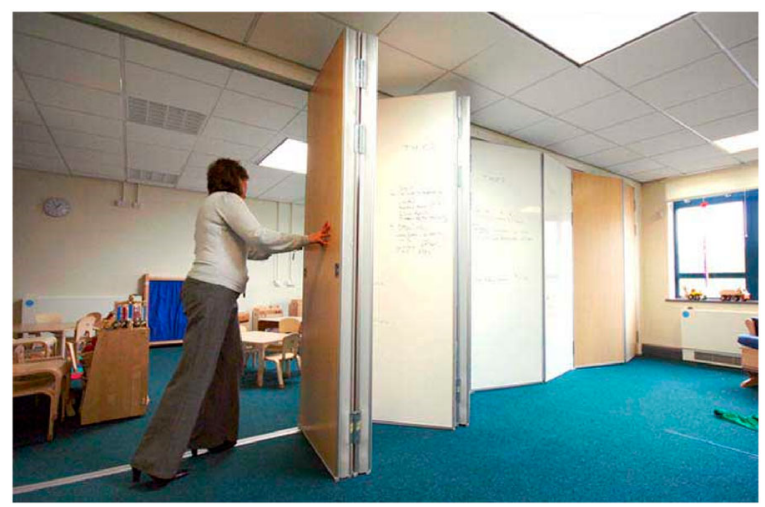

Figure 2. Example of removable partition wall (Dividers, 2014). 
(a)

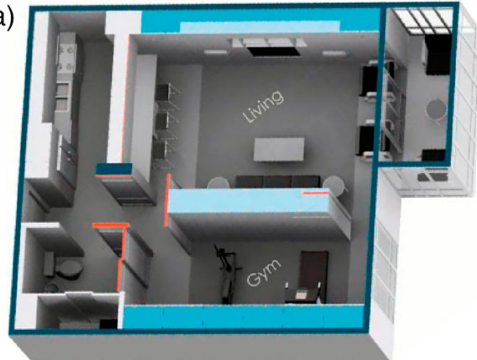

(c)

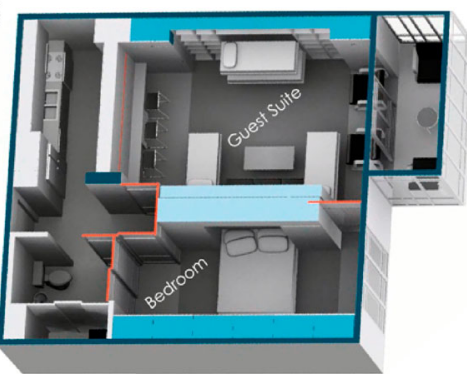

(b)

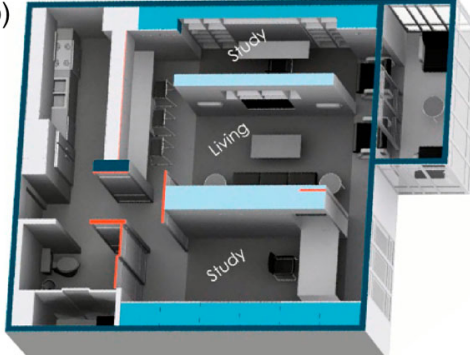

(d)

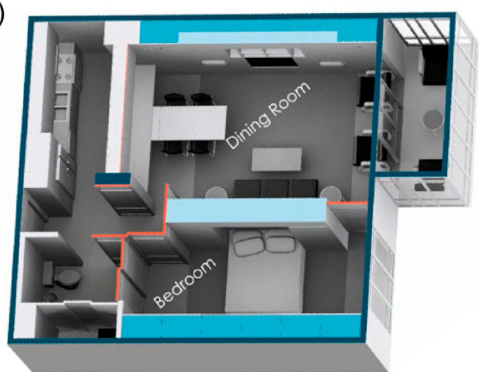

Figure 3. Examples of different layouts of apartment in project CityHome of MIT Changing Places Group (MIT, 2014).

spaces (MIT, 2014). Figure 3 presents 4 out of 10 possible layouts of the same apartment using RoboWalls and efficient furniture design that allow changing the number and area of compartments according to the desires of the occupants. These layouts are not static; all use the same elements that change places and forms over the course of the day (MIT, 2014).

There are some examples of the application of RoboWalls. Figure 4(a) and 4(b) shows the application of these concepts in an existing apartment referred to as the Morphing Apartment,

(a)

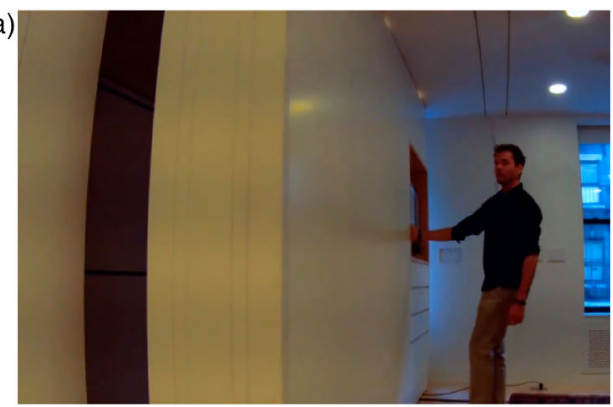

(c)

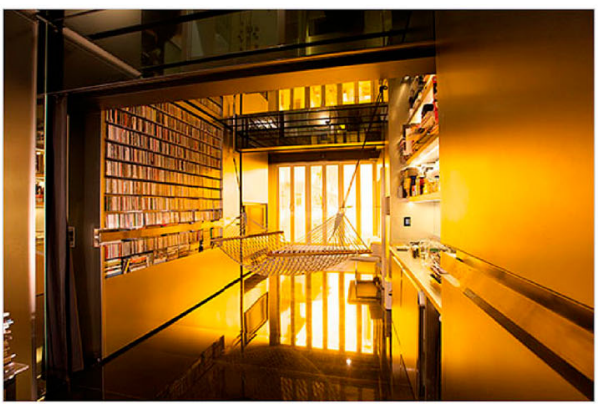

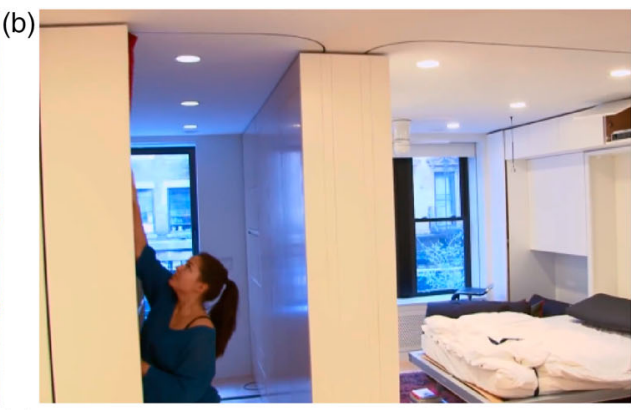

(d)

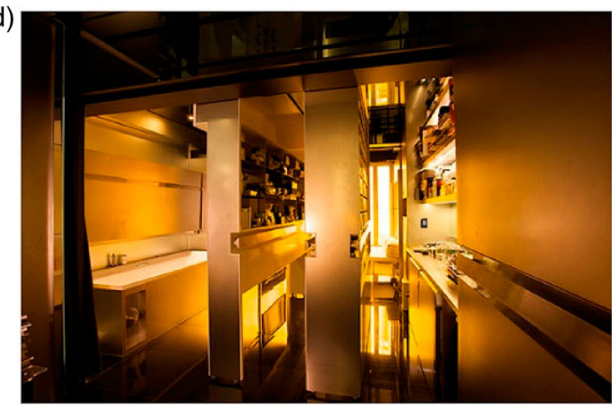

Figure 4. Examples of the use of RoboWalls and adaptable furniture (Designboom, 2013a; Faircompanies, 2012). 

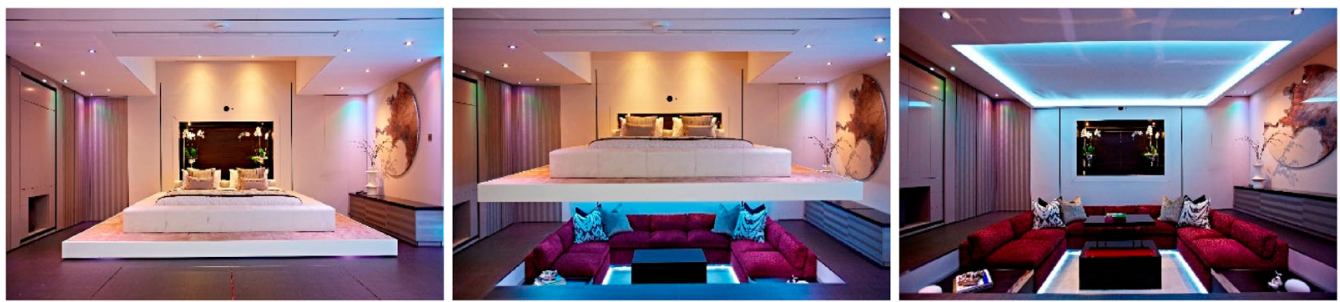

Figure 5. Transformation of a bedroom into a living room using the Yo! Home concept (Woodroffe, 2012).

which is similar to the Lego Style Apartment using adaptable and efficient furniture. It is fully functional in just $39 \mathrm{~m}^{2}$, but also uses a RoboWall to divide the main compartment of the apartment, transforming two rooms into a bigger living room (Faircompanies, 2012). The same strategy is used by architect Gary Chang in his own apartment in Hong Kong, in which he uses sliding walls with automated mechanisms and embedded adaptable furniture to create a multi-use apartment consisting of 24 rooms in just $30 \mathrm{~m}^{2}$ (Figure 4(c) and 4(d)) (Designboom, 2013a).

This trend related to the use of smart interior design to improve quality of small spaces can be further confirmed by the concept of the Yo! Home (Woodroffe, 2012). Yo! Home was developed in the UK by Simon Woodroffe and consists of an apartment, typically between 40 and $75 \mathrm{~m}^{2}$, in which a system of counterweights and hydraulic mechanisms are used to transform a single space into several different rooms. The system innovates by using moveable floors that can be raised to reveal new compartment types, transforming the apartment over the course of the day to suit occupant needs (Figure 5).

\section{Smart interior design and LUE}

To be able to predict the implications of smart interior design on land use, it is first necessary to be able to quantify the building's impact on land use. Considering a previous study (Barbosa et al., 2014a) an index was developed for the assessment of LUE of buildings (Barbosa et al., 2014a). The calculation method suggests that the habitable area and the number of occupants are important to LUE. The calculation method and the definitions of the variables are described as:

$$
\mathrm{LUE}=\frac{\mathrm{FA} \times \mathrm{OC}}{\mathrm{GFA} \times \mathrm{IA} \times \mathrm{AA}} .
$$

- Gross Floor Area (GFA): It is the area of the total surface of the building, measured by the external perimeter of exterior walls and includes balconies.

- Functional Area (FA): It is the area of all compartments of the building, measured by the internal perimeter of external walls, not including internal walls, ducts, vestibules, interior corridors, bathrooms, storage areas, other compartments of similar function and closets in the walls.

- Allotment Area (AA): Area of terrain, resulting from an allotment operation approved under the current legislation.

- Implantation Area or Deployment Area (IA): Area resulting from vertical projection of the building in a horizontal plan, measured by the external perimeter of exterior walls, including basements and attachments, excluding balconies, parapets, peaks, eaves and porches.

- Number of Occupants (OC): Predicted number of occupants of the building.

Considering this index, buildings will perform better the higher the values for the relation between FA and GFA (SE) and also for the number of occupants of the building. Lower values for the area of the building footprint and the empty areas in the allotment would also improve the buildings impact on 
land use. Consequently, in order to improve LUE, buildings should have high density regarding both the constructed areas and the occupants' density. High-rise buildings seems to be a viable solution, but several authors have expressed concerns about the height limit for buildings to be considered sustainable (van den Dobbelsteen \& de Wilde, 2004; Rovers, 2008). Super-tall buildings, therefore, may not be a responsible solution to sustainability.

The implementation of solutions of smart interior design such as the ones proposed earlier would have a direct impact on the results obtained by the application of the equation. Spacesaving solutions would increase the SE of the building, caused by a better arrangement of the spaces and consequent reduction of non-FAs. At the same time, there would be a reduction of the buildings GFA, since the buildings require less area. In consequence, the buildings IA and consequently the AA could also be reduced. Taking this in consideration, it can be argued that the implementation of solutions of smart interior design would promote buildings with increased LUE. As Rovers (Rovers et al., 2011) put it, "every square meter in the system area must be evaluated".

\section{Possible drawbacks of smart interior design}

One possible disadvantage of smart interior design is the possibility of discomfort due to the reduction of the habitable space. It is still necessary to perform comfort and social studies, real size tests supported with questionnaires and interviews to analyse the response of building occupants to this new concept of building design. Regarding the apartment transformation techniques, one possible problem is the discomfort in the need to transform the apartment over the course of the day, which is not instantaneous. Nevertheless, the transformation of the compartment can be done relatively fast using electric motors in the RoboWalls in response to voice commands, mobile phone or computer instructions. The systems can also be handled manually (with little physical effort) in case of energy outage or if it is the occupants desire to operate them in this way. Another challenge is that the automated mechanisms rely on the tidiness of the apartment since there cannot be elements obstructing the free arrangement of the furniture. The mechanisms would need to be correctly programmed with safety measures and communication methods with the occupants. For example, if one wall was obstructed by an object on the ground, the mechanism would not allow the wall to slide and it would communicate with the occupants asking them to remove the object. Sensoring would become an important factor to allow a live response from the mechanisms in case of obstacle detection, collision with objects or detection of possible object falls from shelves during the movement of walls. One significant challenge is to allow the userfriendly transformation of the apartment to be very fast and without major effort by the occupants. The objective is to increase the functionality of the living space without reducing the comfort levels of the occupants.

There are many other aspects to consider regarding the proposed techniques for smart interior design. For example, the durability of the materials and mechanisms was never tested and the existing cases are still very recent. Additionally, there is no knowledge about the maintenance requirements of these systems compared to standard buildings. Also a comparative life cycle assessment study should be made to analyse the difference in environmental impacts between buildings using smart interior design techniques and buildings with standard design. Nevertheless, following a top-down approach in which each topic is addressed separately according to the associated impacts (Lützkendorf et al., 2012) focuses only on proving the argument that it is possible to improve buildings' impact on land use using smart interior design techniques. The use of materials for the mechanical devices may also bring some implications for land use regarding the extraction of raw materials. However, these may be compensated due to the reduced need for construction materials in buildings using smart interior design techniques. 


\section{Comparison between standard buildings and buildings using smart interior design techniques}

\section{Methodology}

To test the argument that the use of solutions of smart interior design and space-saving techniques can increase LUE, this work considers these innovative concepts in the development of an alternative design for an existing residential building. In this case a residential building was used for the comparison, but the same strategy may be used in any type of building in which it is possible to implement smart interior design features. The design alternative was designed taking into consideration the same number of apartments and the same vertical circulation system (stairs and elevators) as the original building. Changes were made only to the interior design of the apartments, which thanks to the use of smart interior design features, required less area compared to the reference building. It was then possible to compare the performance of the original design and the alternative using the calculation methods described earlier. It is important to state that while the technologies used in the design of the alternative are available; the alternative building design only exists as a theoretical design developed for the purpose of this research.

\section{Description of case study}

The case study building is an existing five-storey residential building near the city of Porto in Portugal (Figure 6). The building is composed by four aggregated blocks of two apartments with similar design. For each group of two apartments in each block, the living rooms and the kitchens are very similar. All apartments have a kitchen and a living room at the south façade and rooms in the north façade, with bathrooms in the centre. The difference between the two apartments in each group is that one apartment has three bedrooms and two bathrooms and the other has two bedrooms and one bathroom. This building can be considered a standard building from the point of view of the interior design since all building functions are located in a dedicated and exclusive compartment and it uses common pieces of furniture. Considering this, the standard interior design of this building can be considered representative of most existing residential buildings, independently of the layout of the compartments.

\section{Development of the design alternative}

The proposed design for the building implementing space-saving techniques is presented in Figure 7. This design alternative uses RoboWalls similar to those used in the case of the Morphing Apartment, but it also uses other techniques, such as efficient furniture, folding walls, embedded sliding doors and home automation. The layout of the design alternative is similar for all apartments of the building and consists of two main compartments, the first consists of two bathrooms in the north façade and the second is a single transformable compartment with roughly $33 \mathrm{~m}^{2}$ at the south. This

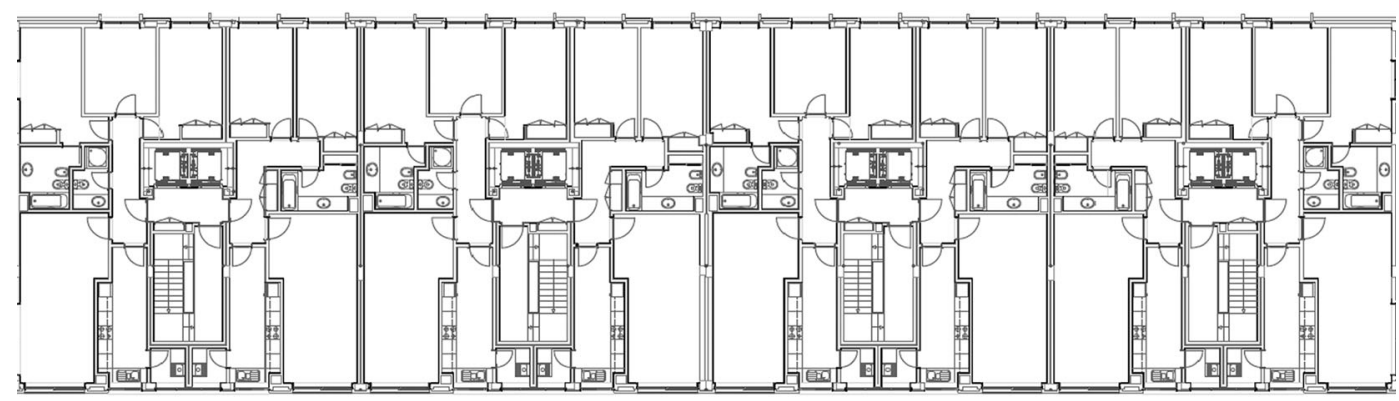

Figure 6. Original layout of case study building. 


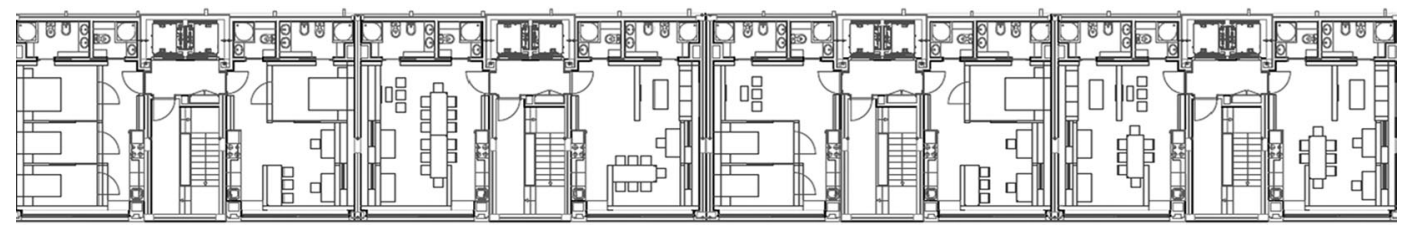

Figure 7. New building layout of case study using several space-saving techniques and having several design possibilities in each apartment.

compartment allows the apartments to be transformed throughout the day in response to the occupants' desires. In consequence, the area of each apartment was reduced from an average of $90 \mathrm{~m}^{2}$ in the original building to $42.4 \mathrm{~m}^{2}$ in the design alternative. Figure 7 (same scale as Figure 6) shows some possible transformations of the apartments, which can range from 3 bedrooms and 1 kitchen to a single compartment working as a big dining room with space for almost 15 persons. There are four separate RoboWalls and two folding walls, which provide a large number of combinations for the interior design of the compartment. The new layout provides two bathrooms and three bedrooms, one of them with a double bed and a private bathroom. Compared to the original design there is one extra bedroom and one extra bathroom for each group of two apartments. The GFA of each group of two apartments, including the vertical circulation elements is $234 \mathrm{~m}^{2}$ for the original design and $129 \mathrm{~m}^{2}$ for the new design.

\section{Performance assessment and comparison of results}

To compare the performance of the original design of the building to the new design alternative, the variables of the equation of LUE were measured. The values of the measurements, as well as the results of the calculation of LUE are presented in Table 1.

The new design alternative showed a reduction in the IA and in the GFA of about 45\%. The FA was reduced by $54 \%$, while there was a $14 \%$ increase in the number of occupants. It is possible to conclude that the design alternative, using smart interior design and space-saving techniques, has a higher value for LUE $\left(5,54 \mathrm{E}^{-05} \mathrm{oc} / \mathrm{m}^{4}\right)$ when compared to the case study building with standard design $\left(3,44 \mathrm{E}^{-05} \mathrm{oc} / \mathrm{m}^{4}\right)$, which indicates better performance than the existing building of about $60 \%$. This calculation considers the same AA for both cases. But considering that the IA was reduced from 925 to $513 \mathrm{~m}^{2}$, it could be considered that the AA could also be reduced to maintain the same proportion to the IAs. If it is considered a proportional reduction (45\%) in the AA (from 2580 to $1431 \mathrm{~m}^{2}$ ), the value of LUE for the new design would be $9,98 \mathrm{E}^{-05} \mathrm{oc} / \mathrm{m}^{4}$, which represents a substantial increase (third column in Table 1). One aspect that is important to mention is that the area of the RoboWalls and other adaptable furniture predicted in the design alternative was considered in the measurement of the FA of the new design alternative. This amount has some influence, since RoboWalls have a predicted thickness of $20 \mathrm{~cm}$ to add to the $30 \mathrm{~cm}$ of furniture thickness in the wall from which beds are set and additional $20 \mathrm{~cm}$ storage furniture around the rest of the apartment

Table 1. Calculation data from the original building and the new layout.

\begin{tabular}{lccc}
\hline Original layout & New layout & $\begin{array}{c}\text { New layout (considering reduced } \\
\text { AA) }\end{array}$ & $\begin{array}{c}\text { Original layout (considering furniture area in } \\
\text { calculation of FA) }\end{array}$ \\
\hline AA: $2580 \mathrm{~m}^{2}$ & AA: $2580 \mathrm{~m}^{2}$ & AA: $1431 \mathrm{~m}^{2}$ & AA: $2580 \mathrm{~m}^{2}$ \\
IA: $925 \mathrm{~m}^{2}$ & IA: $513 \mathrm{~m}^{2}$ & IA: $513 \mathrm{~m}^{2}$ & IA: $925 \mathrm{~m}^{2}$ \\
GFA: $4751 \mathrm{~m}^{2}$ & GFA: $2688 \mathrm{~m}^{2}$ & GFA: $2688 \mathrm{~m}^{2}$ & GFA: $4751 \mathrm{~m}^{2}$ \\
FA: $2786 \mathrm{~m}^{2}$ & FA: $1231 \mathrm{~m}^{2}$ & FA: $1231 \mathrm{~m}^{2}$ & FA: $2360 \mathrm{~m}^{2}$ \\
OC: 140 oc & OC: 160 oc & OC: 160 oc & OC: 140 oC \\
LUE $=3,44 \mathrm{E}^{-05}$ oc/ & LUE $=5,54 \mathrm{E}^{-05}$ oc/ & LUE $=9,98 \mathrm{E}^{-05}$ oc $/ \mathrm{m}^{4}$ & LUE $=2,91 \mathrm{E}^{-05}$ oc $/ \mathrm{m}^{4}$ \\
$\mathrm{~m}^{4}$ & $\mathrm{~m}^{4}$ & & \\
\hline
\end{tabular}


(except the kitchen). In the original design, the area of the furniture was not considered in the measurement of FA. If furniture (such as beds, nightstands, commodes, sofas and tables) in the original design was accounted for, the calculated FA would be $2360 \mathrm{~m}^{2}$ (a loss of about $20 \mathrm{~m}^{2}$ for each group of 2 apartments), which would reduce the value of LUE of the original building to $2,91 \mathrm{E}^{-05} \mathrm{oc} /$ $\mathrm{m}^{4}$ (fourth column in Table 1). This means that from a conventional building to one using smart interior design techniques, the LUE can be improved by a factor of three or more (from 2,91 $\mathrm{E}^{-05}$ $\mathrm{oc} / \mathrm{m}^{4}$ in the original design to $9,98 \mathrm{E}^{-05} \mathrm{oc} / \mathrm{m}^{4}$ in the design alternative).

\section{Conclusions}

Results obtained by the assessment of LUE of the original building and a proposed design alternative using smart interior design features indicate that the design alternative is better than the original. Considering this, it is possible to conclude that the interior design of buildings can affect land use and that the use of smart interior design techniques can greatly improve building sustainability. The potential savings are significant, not only regarding LUE, as demonstrated in this work, but also in other environmental impacts. For example, with a reduction in the GFA, smart interior design techniques would allow buildings to consume less building materials. Considering also the overall weight reduction of the building it may be possible in some situations to also reduce the size of the structural elements. Moreover, the reduction in the interior volume of the buildings would reduce the energy needed for thermal comfort, air circulation and lightning. However, the use of automated systems to transform the compartments of the building may potentially increase the initial cost of the building. Additional initial costs can be compensated by the reduced costs in building materials and the lower costs associated with reduced energy consumption of the building when viewed in a whole life context. Moreover, as these systems become more common and start to be produced on an industrial scale they will, no doubt, become less expensive.

There are challenges for the implementation of smart interior design techniques related to the mechanisms and technologies and also to the comfort of the occupants. Nevertheless, the maturation of these systems will eventually solve the technical issues and as people become used to this new concept the conditions for easier implementation would be created. The examples provided and the design alternative developed in this work may be extreme cases among many possibilities of the combination of movable walls, adaptable and efficient furniture and other space-saving techniques. Probably a mid-term alternative would be more easily accepted by the general public and at the same time still reduce buildings' impact on the environment. Nonetheless, the objective of this work was to demonstrate mathematically that these space-saving techniques could increase the sustainability of the built environment by increasing LUE.

Smart interior design techniques may be a viable solution for small apartments existing in big cities where the prices are very high and in which compact apartments are becoming more commonplace. With the increasing necessity to reduce the environmental footprint of the construction sector the techniques presented in this work provide a viable alternative to more conventional practices.

\section{Disclosure statement}

No potential conflict of interest was reported by the authors.

\section{ORCID}

José Amarilio Barbosa (D) http://orcid.org/0000-0002-7622-1796

Catarina Araújo (1) http://orcid.org/0000-0003-3509-8290

Ricardo Mateus (D) http://orcid.org/0000-0003-2973-8175

Luís Bragança (D) http://orcid.org/0000-0003-4246-8157 


\section{References}

Amado, M. P., \& Ribeiro, M. R. (2011). Urban sprawl promoted through master planning. Paper presented at the World Congress of Sustainable Building, Helsinki, Finland.

Arribas-Bel, D., Nijkamp, P., \& Scholten, H. (2010). Multidimensional urban sprawl in Europe: A self-organizing map approach. Computers, Environment and Urban Systems, 35(4), 263-275. doi:10.1016/j.compenvurbsys.2010.10.002

Barbosa, J., Araújo, C., Mateus, R., \& Bragança, L. (2015). Study of the concept of community buildings and its importance for Land Use Efficiency. Paper presented at the EURO-7, Portugal.

Barbosa, J., Bragança, L., \& Mateus, R. (2014a). Assessment of land use efficiency using BSA tools: Development of a new index. Journal of Urban Planning and Development, 04014020. doi:10.1061/(ASCE)UP.1943-5444.0000208

Barbosa, J., Bragança, L., \& Mateus, R. (2014b). New approach addressing sustainability in urban areas using sustainable city models. International Journal of Sustainable Building Technology and Urban Development. doi:10.1080/2093761X. 2014.948528

Bragança, L., Vieira, S. M., \& Andrade, J. B. (2014). Early stage design decisions: The way to achieve sustainable buildings at lower costs. The Scientific World Journal, 8. doi:10.1155/2014/365364

Day, J., Theodorson, J., \& Van Den Wymelenberg, K. (2012). Understanding controls, behaviors and satisfaction in the daylit perimeter office: A daylight design case study. Journal of Interior Design, 37(1), 17-34. doi:10.1111/j.19391668.2011.01068.x

Designboom. (2013a). Gary Chang on urbanism and his metamorphic apartment. Retrieved 2015, from http://www. designboom.com/architecture/gary-chang-on-urbanism-and-his-metamorphic-apartment/

Designboom. (2013b). Pop-up interactive apartment by students at TU delft. Retrieved from http://www.designboom. com/readers/pop-up-interactive-apartment-by-students-at-tu-delft/

Dividers. (2014). Operable walls project gallery. 2014. Retrieved from http://www.dividersfp.com/content/operablemovable-walls/operable-walls-gallery.html

van den Dobbelsteen, A., \& de Wilde, S. (2004). Space use optimisation and sustainability-environmental assessment of space use concepts. Journal of Environmental Management, 73(2), 81-89. doi:10.1016/j.jenvman.2004.06.002

Faircompanies. (2011). Lego-style apartment transforms into infinite spaces. Retrieved 2014, from http://faircompanies. com/videos/view/lego-style-apartment-transforms-into-infinite-spaces/

Faircompanies. (2012). 6 rooms into 1: morphing apartment packs 1100 sq ft into 420. Retrieved 2014, from http:// faircompanies.com/videos/view/6-rooms-into-1-morphing-apartment-packs-1100-sq-ft-into-420/

Habibi, S., \& Asadi, N. (2011). Causes, results and methods of controlling urban sprawl. Procedia Engineering, 21, $133-141$. doi:10.1016/j.proeng.2011.11.1996

Halleux, J.-M., Marcinczak, S., \& van der Krabben, E. (2012). The adaptive efficiency of land use planning measured by the control of urban sprawl. The cases of the Netherlands, Belgium and Poland. Land Use Policy, 29(4), 887-898. doi:10. 1016/j.landusepol.2012.01.008

Lee, S. (2012). CO2-based demand-controlled ventilation and its implications for interior design. Journal of Interior Design, 37(2), 19-36. doi:10.1111/j.1939-1668.2012.01073.x

Lützkendorf, T., Hájek, P., Lupíšek, A., Immendörfer, A., Nibel, S., \& Häkkinen, T. (2012). New trends in sustainability assessment systems - based on top-down approach and stakeholders needs. International Journal of Sustainable Building Technology and Urban Development, 3(4), 256-269. doi:10.1080/2093761X.2012.747113

McCoy, J. (2012). Sustainability: Environmentally responsible interior design. Journal of Interior Design, 37(1), 5-6. doi:10. 1111/j.1939-1668.2011.01070.x

Massachusetts Institute of Technology (MIT). (2014). Changing places, MIT media lab. Retrieved 2014, from http://cp. media.mit.edu/landing/

Rovers, R. (2008). How tall is a sustainable building? Paper presented at the XXIII UIA World Congress of Architects, Torino, Italy.

Rovers, R., Rovers, V., Leduc, W., Gommans, L., Sap, H., \& van Kann, F. (2011). Urban harvest + approach for 0-impact built environments, case Kerkrade West. International Journal of Sustainable Building Technology and Urban Development, 2 (2), 111-117. doi:10.5390/SUSB.2011.2.2.111

Sorrento, L. (2012). A natural balance: Interior design, humans, and sustainability. Journal of Interior Design, 37(2), ix-xxiv. doi:10.1111/j.1939-1668.2012.01075.x

Woodroffe, S. (2012). Yo! home. Retrieved 2014, from http://yo.co.uk/ 